\title{
INFLUÊNCIA DE JOHN BOYD NA POLÍTICA EXTERNA E DE SEGURANÇA DOS EUA: COSMOVISÃO, TEORIA E GRANDE ESTRATÉGIA
}

\section{John Boyd's Influence in the United States Foreign and Security Policy: cosmovision, theory and grand strategy}

\author{
João Gabriel Burmann da Costa ${ }^{1}$ \\ Igor Estima Sardo ${ }^{2}$ \\ Isadora Bortowski Florisbal ${ }^{3}$
}

\section{Introdução}

O presente trabalho constitui-se como parte do esforço de elaboração de um programa de pesquisa, no sentido defendido por Lakatos (1970), baseado nas ideias de John Boyd. Nesse sentido, resume-se a apresentar e esclarecer as ideias desse autor, formuladas originalmente na subárea de Estudos Estratégicos, e a buscar pontos de contato com o campo de conhecimento das Relações Internacionais (RI). Dessa forma, orienta-se à Política Externa e de Segurança (PES) estadunidense, ao procurar relacionar o pensamento de Boyd com teóricos de RI, tanto em uma abordagem idealista, quanto neorrealista.

Defende-se como hipótese que o estudo do pensamento de John Boyd permite traçar relações com autores e ideias que influenciaram a PES dos Estados Unidos (EUA) após 1991. Em termos de uma análise mais aplicada, voltada para a compreensão da atualidade da PES estadunidense, o estudo das ideias de Boyd pode auxiliar no debate em torno de uma Grande Estratégia (GE) dos EUA. Subscreve-se ao argumento de diversos autores (MARTINS; CEPIK, 2014, p.15; PORTER, 2013; RONIS, 2013; MONTGOMERY, 2014; MARTEL, 2015; YETIV, 2008; WALT, 2018) que defendem que desde o fim da Guerra Fria um dos principais problemas dos EUA relacionados a sua PES é a ausência de uma definição política clara sobre sua GE.

O estudo justifica-se, academicamente, ao buscar introduzir o pensamento de John Boyd no debate brasileiro de Relações Internacionais. Trata-se da trajetória intelectual de um reverenciado estrategista nos

\footnotetext{
${ }^{1}$ Professor do curso de Relações Internacionais no Centro Universitário Ritter dos Reis - UniRitter. Mestre em Estudos Estratégicos Internacionais (PPGEEI) UFRGS e bacharel em Relações Internacionais pela mesma Universidade. Email: jgburmann@gmail.com ${ }^{2}$ Graduando em Relações Internacionais na Universidade Federal do Rio Grande do Sul. Email: igorsardo@gmail.com

${ }^{3}$ Graduanda em Relações Internacionais na Universidade Federal do Rio Grande do Sul. Email: isabortowski@gmail.com
} 
Estados Unidos - conforme se verifica em citações coletadas por seus biógrafos (CORAM, 2002; HAMMOND, 2001) -, porém de repercussão restrita ao campo dos Estudos Estratégicos. Nesse sentido, procura-se justificar essa pesquisa, também, ao se propor a divulgação e a ampliação do debate em torno das ideias de Boyd.

Especialmente, nesse caso, ao se buscar elementos que aproximem o pensamento boydiano do debate teórico de Relações Internacionais. Argumenta-se que esses elementos de contato podem ser compreendidos de forma mais clara ao serem relacionados com a PES dos EUA. Isso se deve não só pelo contexto em que elas foram desenvolvidas, mas também pelas décadas de atuação de Boyd como consultor, lobista e conferencista nos círculos políticos e militares estadunidenses.

Assim, o estudo da obra de Boyd pode contribuir para ampliar a compreensão sobre o desenvolvimento de doutrinas militares estadunidenses, bem como da atuação do país em política externa, no contexto do pós-Guerra Fria. Para ficar somente em um exemplo, em que Boyd teve participação direta como consultor, tem-se a Guerra do Golfo de 1991 (CORAM, 2002, p.422-425; BURTON, 2014, p.3). Boyd, já afastado da vida pública, encontrou-se ao menos uma vez com o então Secretário de Defesa dos EUA - e futuro vice-presidente - Dick Cheney (CORAM, 2002, p.422). Além disso, boa parte do vocabulário utilizado pelos porta-vozes militares para se referir à Operação Tempestade no Deserto, advinha de apresentações feitas por Boyd, em expressões como "operar dentro do ciclo de decisão inimigo”.

O ponto inicial da análise é a cosmovisão ${ }^{4}$, a epistemologia ${ }^{5}$ e o método desenvolvido por Boyd. Sua cosmovisão diz respeito ao predomínio do caos, em uma realidade cuja principal característica seria a incerteza e a tendência à desagregação. Disto, Boyd desenvolve seu método, a forma de ação diante dessa realidade: a sistematização de um modelo de tomada de decisão racional, chamado Ciclo OODA (Observação, Orientação, Decisão e Ação). Expostas as principais ideias do autor, parte-se para o esforço de pesquisa propriamente dito, qual seja: a utilização de Boyd como elemento de referência para discussão de cosmovisões completamente diversas, no caso, abordagens idealistas e neorrealistas.

Para tanto, procede-se à confrontação das ideias boydianas com a obra de dois teóricos das Relações Internacionais, um de viés idealista e outro realista, Martin van Creveld e John Mearsheimer. Essa escolha se dá pelo fato que ambos autores, além de serem reconhecidos por suas produções intelectuais no campo das Relações Internacionais, também possuem uma identificação com a área de Estudos Estratégicos, campo em que Boyd enquadra-se originalmente. Além disso, ao se estudar a biografia de Boyd e os debates políticos e acadêmicos em que ele se envolveu ao longo de sua trajetória, é possível identificar intersecções suas com esses dois autores. No caso de Mearsheimer, os dois estiveram em lados opostos em dois debates

\footnotetext{
${ }^{4}$ Cosmovisão - Enquanto uma "visão de mundo", está diretamente relacionada à compreensão ontológica de determinado autor. Ontologia é a teoria do ser em geral (JAPIASSÚ \& MARCONDES, 2008), um "sistema de crenças filosóficas sobre a natureza da realidade social, incluindo o que podemos aprender sobre essa realidade e como podemos fazê-lo" (LEAVY, 2014. p. 3). Marshall (1998, p. 465), define uma ontologia como o inventário de tipos de ser e suas relações, advinda do esforço de compreensão da realidade.

${ }^{5}$ Epistemologia - De acordo com Marsh \& Furlong (2002, p. 18-19), "se uma posição ontológica reflete a visão do pesquisador sobre a natureza do mundo, sua posição epistemológica reflete a visão dele do que se pode-se saber sobre o mundo e como pode-se saber [...]". Para esses dois autores a ontologia e a epistemologia empregadas por um pesquisador são fundamentais, algo impossível de se desvincular por conveniência (a expressão original empregada pelos autores é "a skinnot a sweater", podendo ser traduzida como "uma pele, não um agasalho").
} 
importantes da estratégia militar estadunidense: o Movimento de Reforma Militar e a Guerra de Manobra os quais Boyd defendia e Mearsheimer se opunha. No caso de Creveld, é reconhecido por seus biógrafos que ele e Boyd mantiveram contato e se encontraram algumas vezes (RICHARDS, 2004). Essa colaboração se deu, provavelmente, no tocante aos interesses em comum entre os dois, no que diz respeito aos aspectos de Comando e Controle na guerra - tema sobre o qual Creveld dedicou exclusivamente em um livro (CREVELD, 1987), e Boyd uma apresentação (BOYD, 2005). Além disso, o pensamento de Creveld influenciou, de modo reconhecido, as ideias de Willian Lind, antigo discípulo de Boyd, a formular a Teoria da Guerra de Quarta Geração (LIND et al., 1989), um dos legados mais destacados de parte do pensamento boydiano.

A escolha de dois autores para a comparação foi feita com base em facilitar a aproximação entre formulações distintas da teoria de RI com o pensamento boydiano, que possui uma construção ontológica e epistemológica específica - conforme se pretende demonstrar. Foi nesse sentido que se procedeu com a análise das obras de Creveld e Mearsheimer, ao se selecionar as duas obras principais desses autores: Ascensão e Declínio do Estado (2004) e A Tragédia da Política das Grandes Potências (2007). A partir do estudo das principais propostas e premissas que orientam a construção teórica e normativa de Creveld e Mearsheimer, se procurou identificar elementos que facilitassem a compreensão da ontologia e do método de Boyd. Importa ressaltar que esforços futuros do programa de pesquisa baseado no pensamento de Boyd deverão, preferencialmente, voltar-se para a ampliação do diálogo entre suas ideias e demais aspectos da teoria de Relações Internacionais, bem como a aplicabilidade em demais momentos históricos e objetos de análise.

No que diz respeito à abordagem idealista, o foco da investigação reside no papel do Estado como um mantenedor da ordem no Sistema Internacional (SI). Neste ponto, se antagoniza a cosmovisão boydiana de predomínio do caos - mas com a existência dos Estados - com a visão de Martin van Creveld, que defende o fim do Estado e o surgimento de um sistema internacional hierárquico, com a ordem garantida por um novo governo mundial.

Já na abordagem neorrealista, procura-se levantar componentes paralelos no pensamento de Boyd e no pensamento de John Mearsheimer. Defende-se que a relação entre os dois autores reside no papel atribuído à intimidação e ao medo como fundamentos da projeção de força estatal no Sistema Internacional. Esses dois axiomas ocupam o centro da teoria do neorrealismo ofensivo de Mearsheimer, e podem ser observados nas ações de política externa estadunidense em diversos momentos no pós-Guerra Fria. O objetivo aqui é investigar como o pensamento de Boyd em torno da influência no Ciclo OODA adversário, aliado a esses axiomas, pode ser um condicionante importante desse comportamento.

Por fim, discute-se a utilidade do pensamento de Boyd para o debate em torno da Grande Estratégia dos EUA no pós-Guerra Fria. O conceito de GE diz respeito ao conjunto de medidas, providências e atitudes, independentes do governo, justificadas por um objetivo em comum, que esteja alinhado aos interesses do Estado. Ele inclui não só os componentes do poder militar, como também as capacidades econômicas, culturais e diplomáticas de um país. Uma GE bem definida é importante, pois orienta como determinado Estado agirá no SI, buscando defender seus interesses. Defende-se que as ideias de Boyd podem servir como 
reflexo dos problemas predominantes na formulação e aplicação de uma GE estadunidense: o poderio das soluções simplificadoras, baseadas na inversão da hierarquia da realidade (da tática para a estratégia, do combate para a política), conforme preconizado por Boyd, parece atingir também a consecução da PES dos EUA.

\section{John Boyd: cosmovisão, epistemologia e método}

John Richard Boyd (1927-1997) foi um coronel da Força Aérea dos EUA (USAF), pensador militar e consultor do Pentágono. Ao longo de sua vida, escreveu apenas dois trabalhos, sendo o resto de sua obra composta por um conjunto de apresentações (slides), realizadas ao longo de duas décadas nos meios acadêmicos, políticos e militares dos EUA. Esse conjunto de apresentações é conhecido pelo título de $A$ Discourse on Winning and Losing (BOYD, 2012). A influência de Boyd se deu principalmente no meio militar estadunidense, por meio da defesa da guerra de manobra e da sua Teoria de Energia-Manobrabilidade, utilizada no desenvolvimento de aeronaves como o McDonnell Douglas F-15 Eagle e o General Dynamics F16 Fighting Falcon (CORAM, 2002, p.6; HAMMOND, 2004, p.68).

Seu conceito mais conhecido é um modelo de tomada de decisão racional (SCHECHTMAN, 1996, p.33), o Ciclo OODA, exposto inicialmente na apresentação Patterns of Conflict (BOYD, 1986). Originalmente elaborado em um contexto militar, atualmente o Ciclo OODA é aplicado nos mais diversos campos do conhecimento - graças a diversos seguidores de Boyd: da política, passando pelos negócios, até o esporte. Contudo, o reconhecimento da autoria do conceito nem sempre é dado a Boyd, fato que dificulta o mapeamento da real influência de suas ideias.

Para compreender o funcionamento e a utilidade do Ciclo OODA no pensamento do autor é necessário, anteriormente, discutir sua cosmovisão e epistemologia. Ou seja, sua visão do que é a realidade e o modo como se entende essa realidade. O trabalho que nos permite essa discussão é o artigo Destruction and Creation (BOYD, 1976), uma das suas duas obras escritas. Nele, Boyd ilustra um novo modo de fazer ciência, com um foco maior nos aspectos de mudança, diversidade, evolução, imprevisibilidade, complexidade, incerteza, não-equilíbrio e não-linearidade (OSINGA, 2005, p. 94). Uma das dificuldades na sistematização do pensamento boydiano é a inversão que ocorre na hierarquia entre a ontologia e a epistemologia. Em outras palavras, em seu artigo, parte-se da pergunta "como se faz para conhecer a realidade" e, só então, se coloca a questão acerca de "o que é a realidade".

Essa inversão faz com que sua cosmovisão seja definida mediante inferência: há o predomínio do caos, devido à inexorabilidade do aumento da entropia ${ }^{6}$ - a medida de desagregação de sistemas abertos que elevas as incertezas e complexifica todos os fenômenos aplicados à realidade. Analisando-a, pode se concluir que ela possui um traço ontológico negativo, dissolvente e desagregadora das mediações. Além disso, no limite, supõe a falência das instituições como as conhecemos: a obsolescência do Estado e, portanto, a superação das Forças Armadas. Em outras palavras, a cosmovisão de Boyd é distópica, na medida

\footnotetext{
${ }^{6}$ Entropia - A “entropia é um conceito que representa o potencial de trabalho, a capacidade de ação ou o grau de confusão e desordem associada com qualquer atividade física ou de informação” (BOYD, 1976, p. 5).
} 
em que a única atitude racional possível - dado que tudo muda de forma incontrolável e caótica - é a de acelerar o próprio caos. Isto é, buscar uma forma de governar a entropia.

Como mencionado, essa cosmovisão advém da teoria do conhecimento usada por Boyd para explicar a realidade em Destruction and Creation. Isso é feito mediante três conceitos oriundos da física clássica e quântica: o Teorema da Incompletude e Inconsistência de Gödel, o Princípio da Incerteza de Heisenberg e a Segunda Lei da Termodinâmica (OSINGA, 2005, p.79). O primeiro demonstra que, em certos ramos da Matemática, não se pode comprovar a própria consistência por meio da lógica interna àquele sistema. Ou seja, é impossível abranger um sistema com apenas um sistema único de lógica.

Nas palavras do próprio Boyd (1976, p.6, tradução nossa), as três ideias explicariam a realidade por meio do seguinte percurso:

\footnotetext{
De acordo com Gödel, nós não podemos - no geral - determinar a consistência, ou seja, o caráter ou natureza de um sistema abstrato dentro dele mesmo. De acordo com Heisenberg e a Segunda Lei da Termodinâmica, qualquer tentativa de fazer isso no mundo real, demonstrará a incerteza do sistema e gerará desordem. Tomadas em conjunto, essas três noções reforçam a ideia de que qualquer esforço contínuo e orientado para dentro de melhorar a união do conceito com a realidade observada apenas aumentará o grau de incompatibilidade entre eles.
}

O uso das ideias de Gödel e Heisenberg, como parte da epistemologia de Boyd, servem para legitimar sua interpretação acerca da centralidade da Segunda Lei da Termodinâmica na nossa realidade. Em certa medida, Boyd propõe a ontologização desse princípio, submetendo a ação humana a uma verdadeira limitação, em função da inexorabilidade do aumento da entropia.

Ainda em seu artigo de 1976, o autor propõe uma versão rudimentar do que viria a ser o Ciclo OODA: uma forma de como gerenciar o caos e guiar a ação humana. Boyd afirma que nós desenvolvemos padrões mentais ou conceitos de significados, e que seu objetivo é demonstrar como os humanos destroem e criam esses padrões, de modo a se adaptarem a um meio ambiente em modificação, com recursos limitados. Esse é o principal fator que condiciona o grau de cooperação entre os seres humanos (BOYD, 1976, p.1), visto que o nosso objetivo primordial, enquanto humanos, seria ampliarmos nossa capacidade de ação independente.

Esses conceitos desenvolvidos precisam ser moldados na medida em que a realidade também muda. A partir desse ponto, Boyd busca explicar como conceitos podem ser formados: pela dedução ou pela indução. Pelo processo de dedução, partindo-se do geral para o específico, aplica-se a análise e a diferenciação, como se dentre uma grande quantidade de conceitos e domínios particulares, nós precisássemos quebrar esses domínios. A esse processo, Boyd denomina dedução destrutiva. De forma popular, poderia ser chamada de "pensamento fora da caixa". O adjetivo destrutivo, diz respeito a como se dá a relação entre as partes e o todo, que é destruído para a elaboração de repositórios de saber. No lugar do significado e da ordem, assume a incerteza e a desordem (CORAM, 2002, p. 325).

Após a destruição do todo, faz-se necessário utilizar a indução para reorganizar e reconstruir a ordem e o significado dos conceitos, indo do específico para o geral, por meio da síntese e da integração. A esse processo, Boyd chama indução criativa, que se constitui num processo primordialmente relacionado à 
dedução destrutiva. Juntas, eles se constituem em um ciclo, que seria aplicado de modo contínuo por cada ser humano, de modo a buscar convergência de conceitos e domínios mentais com a realidade em transformação. Esse ciclo de criação de repositórios de conhecimento deve ser constantemente reproduzido, e seus conceitos testados e validados perante a realidade.

A sistematização dessa proposta de ação racional surgiu alguns anos após Destruction and Creation, nas primeiras versões da apresentação Patterns of Conflict (BOYD, 1986). O conceito de Ciclo OODA foi sendo desenvolvido por Boyd ao longo de 20 anos, até a última versão de sua apresentação disponível, em 1996, apenas um ano antes do autor. Esse conceito consiste em seu grande legado metodológico, e foi representado graficamente conforme a Figura 1.

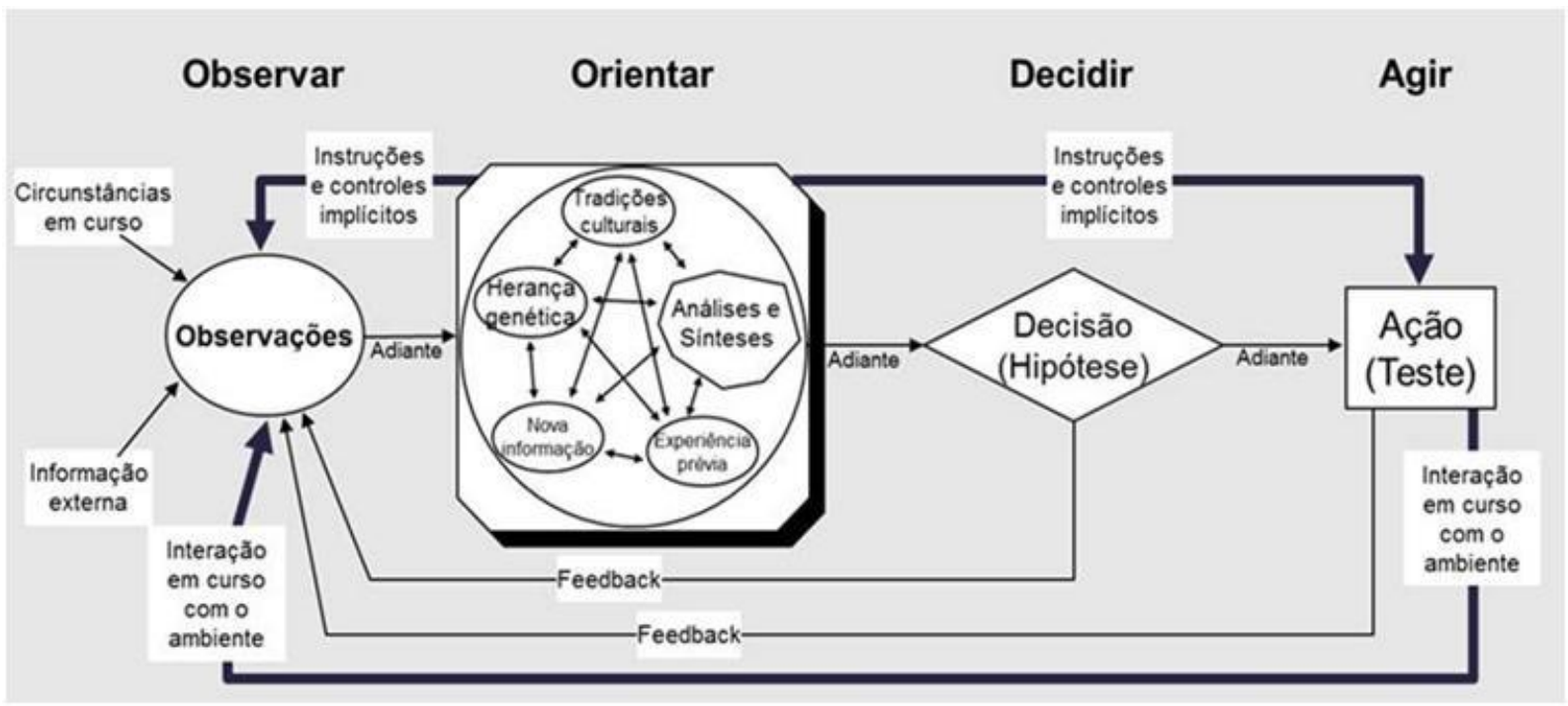

Figura 1: Versão Completa do Ciclo OODA. Fonte: Boyd (2012). Traduzida por Rodrigo Jaroszewski (2017).

A premissa fundamental do modelo é que o processo de tomada de decisão é composto por quatro fases: Observação, Orientação, Decisão e Ação, de onde advém a sigla OODA. Ou seja, o Ciclo OODA consiste na sistematização de um processo de tomada de decisão racional. Sendo assim, todos os seres humanos o desenvolveriam de modo intuitivo - ou deliberado -, a fim de sobreviverem. Ele sintetiza o processo cognitivo humano e o relaciona à competição pela sobrevivência. Portanto, cabe a cada pessoa garantir o funcionamento do seu Ciclo OODA e, na medida do necessário, impedir o funcionamento do Ciclo OODA do oponente. Esse modelo representava, para Boyd, o modo como cada um de nós vence ou perde competições. Dessa forma, o autor busca ressaltar o ser humano como centro do conflito e, portanto, elemento mais importante na guerra.

O primeiro passo do ciclo é a Observação, a percepção de si mesmo e o mundo ao redor. Como destacado por Osinga (2005, p. 271, tradução nossa) a observação é “o método pelo qual os indivíduos identificam a mudança ou a falta de mudança no ambiente ao seu redor" ${ }^{7}$. Por esse motivo, deve ser executada constantemente e constitui-se na fonte primária de novas informações no processo cognitivo.

${ }^{7}$ No original: "It is the method by which people identify change, or lack of change, in the world around them" (OSINGA, 2005, p. 271). 
Já o segundo passo consiste na Orientação ou a capacidade de situar-se no ambiente e de perceber a ação dos demais indivíduos nesse ambiente. Esta etapa é um processo próprio dentro do ciclo, no qual estamos sempre nos orientando. Ou seja, a Orientação preside todo o Ciclo OODA. A Observação e a Orientação podem ser entendidas como a coleta e o processamento dos dados, respectivamente. E estes condicionam a Decisão, que precede a Ação - respectivamente, terceiro e quarto passo.

A Orientação é composta pelo conjunto de imagens, percepções, impressões e, informações moldadas por um processo interativo - inputs. Estes são processados por um conjunto de características dadas de cada indivíduo - carga genética, experiência prévia, aspectos de tradição e cultura - e geram os outputs, que condicionarão a Decisão e a Ação, as quais Boyd relaciona com Hipótese e Teste.

Ou seja, a "Decisão é o componente no qual os atores decidem quanto a ações formuladas na fase de Orientação" ${ }^{8}$ (OSINGA, 2005, p. 271, tradução nossa). Nesse sentido, as ações seriam os testes da hipótese adotada, devendo ser rápidas, ambíguas, ameaçadoras e variadas. Ou seja, devem estar de acordo com as necessidades implicadas por uma realidade caótica, incerta e complexa.

Em suma, a verdadeira intenção de Boyd ao pensar a utilização do Ciclo OODA como modelo de tomada de decisão na guerra é buscar o colapso do inimigo, provocando a sua paralisia, mediante interferência no seu ciclo.

\section{Boyd e Creveld: caos e ordem no Sistema Internacional}

Uma vez exposto o pensamento de John Boyd, propõe-se a comparação de sua cosmovisão com a interpretação idealista das Relações Internacionais de Martin van Creveld (2004). O foco dessa análise é verificar a utilização das ideias de Boyd como elemento de referência para validar o conteúdo normativo da cosmovisão de Creveld, essencialmente diverso da boydiana: o utopismo de um mundo sem Estados.

Em sua obra sobre a ascensão e o declínio do Estado, Creveld defende a tese da derrocada do Estado tal como conhecemos, isto é, o típico Estado Moderno "westfaliano". As conclusões de Creveld advém de sua formação acadêmica na área militar, e mais especificamente, de seus estudos sobre a obsolescência da Teoria da Guerra de Clausewitz (CREVELD, 1991; 2017). Por esse percurso, ele corrobora sua tese de que a função primordial do Estado, definida no século XVII, está perdendo efeito para o avanço desmedido da tecnologia da informação e da comunicação e, sobremodo, para a capacidade desta tecnologia de neutralizar qualquer tipo de conflito entre as Grandes Potências do Sistema Internacional.

No tocante à impossibilidade de embate entre os principais Estados do sistema internacional, Creveld evidencia todo o retrospecto da escalada nuclear do século XX e XXI e da política de Destruição Mútua Assegurada (MAD) como pontos de inflexão para o declínio fatal do Estado (CREVELD, 2004). Outros fatores mencionados pelo autor e que evidenciam o declínio do Estado dizem respeito ao predomínio de atores não estatais em conflitos armados contra forças estatais (CREVELD, 2004, p.565);ao fim do alistamento obrigatório em diversos países ocidentais, dado a diminuição da disposição dos nacionais em lutarem em nome do Estado (CREVELD, 2004, p.590); e a diversos problemas econômicos, relacionados ao

\footnotetext{
${ }^{8}$ No original: "Decision is the component in which actors decide among alternatives that are generated in the Orientation phase" (OSINGA, 2005, p.).
} 
fornecimento de bem estar social. Conforme o próprio Creveld (2004, p.593) afirma, todas essas mudanças acarretam no fim da crença do Estado como uma divindade:

\begin{abstract}
Sejam quais forem os processos exatos, em quase toda parte foram acompanhados por um declínio na disposição dos Estados de assumir a responsabilidade por suas economias, de fornecer benefícios sociais, de educar os jovens, e mesmo de exercer a função elementar de proteger os cidadãos contra o terrorismo e crime, tarefa que na melhor das hipóteses, está sendo repartida com outras instituições e, na pior, simplesmente deixada de lado. [...] Os dias em que, como foi o caso em especial durante a era da guerra total, o Estado podia fazer-se passar por um deus na Terra chegaram claramente ao fim.
\end{abstract}

No lugar do Sistema Internacional de Estados, Creveld propõe um Governo Mundial, que substitua a soberania pelos Direitos Humanos. A territorialidade, outra característica fundamental do Estado moderno, também seria substituída, por redes de corporações, ou "homens artificiais" (CREVELD, 2004, p. 597). Essas redes e comunidades de corporações poderiam vir a ser maiores que os Estados, em um nível regional. Ou então, menores, apenas locais. Podem também pertencer a diversos Estados ou a nenhum, com natureza política ou de outro fim. No geral, teriam como objetivo promover mais direitos e justiça do que seriam capazes os Estados, e avançariam no domínio de capacidades em que os Estados ficaram para trás:

[...] todas têm em comum o fato de estarem mais afinadas com a tecnologia moderna, as comunicações e, em especial, com os transportes, do que o Estado. Em consequência disso, algumas delas são capazes de se tornar muito mais ricas que a maioria dos Estados; ou assumir algumas de suas funções; ou fugir a seu controle criando colônias e levando seus recursos para fora das fronteiras; ou influir mais do que os governos nas opiniões de seus cidadãos; ou (como no caso das inúmeras organizações de guerrilheiros e terroristas) ter êxito na resistência armada; ou, não raro, alguma combinação de todos esses fatores (CREVELD, 2004, pp.597).

Embora esse novo governo mundial mantenha a democracia e seja, em certa medida, autogestionário, ele se constituiria em um sistema completamente diferente do anterior. No lugar da anarquia predominante entre os Estados, ascenderia o governo hierarquizado como princípio de ordem, orientado pela racionalidade, tendo em vista o bem comum.

É nesse sentido que a cosmovisão de Creveld antagoniza com a de Boyd, ainda que existam elementos de proximidade entre as duas. Afinal, no limite, o predomínio do caos - preconizado por Boyd levaria à obsolescência do Estado, talvez até mesmo a sua destruição. Paradoxalmente, Creveld parece vislumbrar um mundo em que a ausência de Estados traria mais ordem do que na anarquia, e não o caos.

Todavia, essa visão utópica de Creveld também guarda semelhanças com a cosmovisão distópica de Boyd: ambas possuem um conteúdo metodológico negativo, desagregador das mediações, em que se supõem a falência das instituições como as conhecemos. A questão da guerra é também um elemento de divergência entre os dois autores. Não se pode inferir pela obra de Boyd que ele vislumbrasse a superação da guerra como expediente da ação humana no Sistema Internacional. Pelo contrário, o conflito é um elemento essencial de sua cosmovisão e de seu método, constituindo-se em uma das principais formas de interferir no Ciclo OODA adversário. É justamente devido ao papel destruidor da guerra, que se pode atribuir à cosmovisão boydiana a alcunha de distópica: a guerra, quando assume o sentido de meio e de fim da ação estatal no SI, só pode levar ao caos. 
Já Creveld, por sua vez, conjectura um mundo onde o fim do Estado a superação da guerra e o predomínio da paz como elemento de ordem do governo mundial. É feita uma distinção entre áreas onde o recuo do Estado se dará de modo pacífico, e as áreas menos afortunadas, onde "na melhor das hipóteses, o ressurgimento do 'mercado' à custa dos controles administrativos e do bem estar social significará segurança reduzida e, quase sempre, mais desordem” (CREVELD, 2004, pp. 603). Os motivos dessa distinção não são bem expostos, mas não é absurdo supor, considerando o resto da argumentação do autor, de que o fato da democracia ser mais bem desenvolvida em alguns locais do que em outros, possa condicionar essa "transição".

De qualquer modo, a investigação da semelhança entre esse aspecto do pensamento de Creveld com a teoria da paz democrática, defendida por uma corrente de autores da escola liberal de RI, principalmente Russet (1993), parece uma abordagem promissora para trabalhos futuros.

\section{Boyd e Mearsheimer: medo e projeção de força}

Defende-se aqui que o pensamento de John Boyd também permite investigações que busquem similitudes com a teoria neorrealista de Relações Internacionais. Importa destacar que essas investigações não têm como objetivo determinar a influência de um sobre o outro, dado que Boyd não era um teórico de Relações Internacionais. Trata-se, portanto, de encontrar elementos de proximidade que permitam esclarecer algumas hipóteses basilares ou auxiliares da tradição neorrealista, que encontra na obra de Waltz (1979) o lançamento seminal do modelo estrutural de política internacional. No que concerne a esse trabalho, o esforço reside em relacionar, principalmente, aspectos do método boydiano - relacionados à instrumentalização do Ciclo OODA e a interferência no ciclo adversário - com a teoria neorrealista ofensiva de John Mearsheimer, expostos no livro The Tragedy of Great Power Politics.

Com o fim da bipolaridade, Mearsheimer centra suas pesquisas na política internacional pós-Guerra Fria, destacando a impossibilidade de existira unipolaridade plena de qualquer superpotência. A principal razão fornecida pelo autor é pelo fato de que a anarquia sempre foi e será inerente ao Sistema Internacional, e que Grandes Potências só podem atingir o status de Hegemonias Regionais (MEARSHEIMER, 2007, p. 4041). Tendo em vista a anarquia do sistema, a incerteza perante a própria autopreservação e segurança, os Estados buscam ampliar ainda mais sua segurança, por meio da maximização de interesses e da construção de capacidades militares ofensivas (MEARSHEIMER, 2007, p. 30-31). Dentro dos princípios do realismo estrutural de Waltz, Mearsheimer afirma que as grandes potências se receiam mutuamente devido à anarquia e à dificuldade de analisar as intenções dos outros atores estatais. Ou seja, os Estados sempre irão contrabalançar as capacidades dos demais e não suas intenções. Nessa lógica, quanto mais poder um Estado possui, mais medo ele causará dentre os adversários (MEARSHEIMER, 2007, p. 56).

Entretanto, considerando as ações reais dos Estados no Sistema Internacional, incluindo os Estados Unidos, o conceito de medo na teoria de Mearsheimer parece fugir do caráter racional e analítico, relacionado à balança de poder entre capacidades militares ofensivas. Como afirma Pashankhanlou (2017, p. 17, tradução nossa), o medo é “uma reação espontânea a uma ameaça ou a um perigo percebido, que cria 
uma necessidade intensa de autopreservação" $0^{9 "}$. Ou seja, trata-se de um fator completamente subjetivo, e cujos motivos podem variar completamente, a depender das circunstâncias. Nesse sentido, o conceito de medo parece ser redundante e estar em detrimento da abordagem sistêmica de Mearsheimer (PASHANKHANLOU 2017, p. 109).

Independente da consistência ou inconsistência do conceito de medo na teoria de Mearsheimer, o fato é que ela ocupa uma parte essencial das suas hipóteses relacionadas à projeção de força das Grandes Potências. Esse é o fato que interessa para efeitos de comparação com o pensamento de Boyd, uma vez que o centro da estratégia para Boyd reside justamente na busca pelo rompimento do ciclo OODA adversário, mediante a criação de pavor, por meio de imagens mentais que busquem fazer o adversário se desorientar e concluir que o melhor é não se opor àquela ameaça:

penetrar o ser moral, físico e mental para dissolver sua fibra moral, desorientar suas imagens mentais, corromper suas operações e sobrecarregar seu sistema - assim como subverter, quebrar, apreender, ou subjugar esses bastiões, conexões ou atividades morais, mentais, e físicas - de modo a destruir a harmonia interna, produzir a paralisia, e colapsar a vontade do adversário em resistir (BOYD, 1986, p.113, tradução nossa ${ }^{10}$ )

O conceito de medo e a tese de projeção de força mediante construção de capacidades ofensivas, na teoria de Mearsheimer, aliada à compreensão de estratégia e a lógica por trás do método em Boyd, constituem-se em uma combinação potencialmente danosa, ao ser aplicado na PES de algum Estado. Ainda que Mearsheimer não seja um defensor de ações preemptivas, e tenha se oposto a uma guerra contra o Iraque em 2003 (MEARSHEIMER et al, 2002), por exemplo, suas ideias parecem ter influenciado, indiretamente, as ações de política externa do governo Bush e as políticas de Transformação do Militar do secretário de Defesa, Donald Rumsfeld.

Naturalmente, o impacto da confluência das ideias de ambos os autores requer um estudo mais aprofundado e com melhor seleção de casos. Importa considerar, que os dois autores estiveram em lados opostos em alguns debates, especialmente no relacionado a abordagem estadunidense frente aos soviéticos no Fronte Central da OTAN durante a década de 1980 (MEARSHEIMER, 1982) e quanto ao Movimento de Reforma Militar (MEASRHEIMER, 1983). Além disso, precisa considerar outros fatores, como as doutrinas militares vigentes na época dos casos selecionados e uma análise operacional de cada caso. Essa linha de investigação deve ser contemplada em futuras pesquisas do programa de pesquisa envolvendo o pensamento de John Boyd.

\footnotetext{
${ }^{9}$ No original: “a spontaneous reaction to a perceived threat or danger which creates an intense urge to defend oneself from that threat or danger".

${ }^{10}$ No original: "Penetrate adversary's moral-mental-physical being to dissolve his moral fiber, disorient his mental images, disrupt his operations, and overload his system-as well as subvert, shatter, seize, or otherwise subdue those moral-mental-physical bastions, connections, or activities that he depends upon-in order to destroy internal harmony, produce paralysis, and collapse adversary's will to resist."
} 


\section{A Grande Estratégia dos EUA no pós-Guerra Fria e a ausência de uma definição política}

Discutidas as possíveis relações entre o pensamento de Boyd e Creveld, na perspectiva idealista, e entre Boyd e Mearsheimer na tradição realista, o foco do debate nesse momento será a PES dos EUA. Mais especificamente, a discussão em torno de uma grande estratégia estadunidense no pós-Guerra Fria.

A Grande Estratégia diz respeito ao nível mais alto de planejamento no âmbito dos Estados modernos, devendo indicar os fins e meios no curto prazo, seja de guerra ou paz, para garantir a sobrevivência do Estado (PORTER, 2013; SIMIONATO, MACHADO, 2015, p. 2). Martins e Cepik (2014, p.18) afirmam que "em seu limite superior, [a Grande Estratégia] é definida pela Constituição e pelas instâncias de coordenação entre os formuladores das políticas de defesa, relações exteriores, segurança institucional e inteligência”. A formulação de uma grande estratégia, portanto, diz respeito a diversos setores do governo, devendo representar uma variedade de grupos de interesse da sociedade e levar em consideração capacidades militares, diplomáticas e econômicas, para indicar a forma de atuação do Estado no SI.

A hipótese defendida aqui parte da análise de Martins e Cepik (2014), que tratam sobre a ausência de uma definição política sobre a grande estratégia dos EUA no pós-Guerra Fria. Isso significa que necessariamente a inexistência de uma grande estratégia, ou de aspectos mais visíveis da PES que poderiam ser considerados como sendo uma. Significa, conforme esses autores, que a ausência de uma definição clara de GE, estabelecida por meio de um debate amplo e por múltiplas abordagens, faz com que a PES estadunidense "seja ditada por conceitos operacionais (tais como a ASB [Air-SeaBattle]), ou pior, por critérios procedimentais, técnicos e táticos” (MARTINS, CEPIK, 2014, p.15). Benjamin Friedman e Justin Logan (2016) também parecem reforçar essa visão, ao tratar do predominante enfoque operacional que formuladores e tomadores de decisão dos EUA adotam, para manter sua primazia.

Para auxiliar na compreensão desse aspecto, cabe recorrer a história da PES estadunidense. Ao longo dos séculos XIX e XX são inúmeros os casos das chamadas doutrinas presenciais. Ainda no século XIX temos a Doutrina Monroe, que inaugura a PES dos EUA voltada as Américas, deixando clara sua posição frente ao colonialismo europeu. No início do século XX tem-se o corolário Roosevelt, ainda dentro da Doutrina Monroe, que irá alterar as práticas estadunidenses e o próprio conteúdo normativo dessa doutrina. Ao longo da década de 1910 e 1920 os EUA voltam-se ao debate entre isolacionismo ou universalismo, sintetizado pelos Quatorze Pontos do Presidente Wilson e pela negativa do Senado ao ingresso do país na Liga das Nações. Esses casos, ainda que mais distantes e com o benefício da análise histórica, nos permitem compreender de que forma as intenções de ação externa dos EUA eram declaradas e podiam ser entendidas (HOOKER, 2014).

Ao avançarmos para um período histórico mais recente, pós-Segunda Guerra Mundial, pode-se falar verdadeiramente de uma Grande Estratégia moderna. Ou seja, formulada e decidida após um processo mais ou menos estruturado, transparente e especializado, envolvendo a burocracia estatal e demais grupos de interesse da sociedade. Tal processo de formulação é consequência, sem dúvidas do grau de institucionalização que o poder Executivo e as Forças Armadas precisaram adquirir, como resultado da Segunda Guerra. Mas também, incentivada pela necessidade de um planejamento que orientasse a ação do 
país em um SI marcado pela existência clara e declarada de um adversário também com o status de superpotência. Os marcos dessa Grande Estratégia podem ser encontrados no processo de formulação da NSC 68, de 1950, durante a administração Truman. Tratava-se de um documento, formulado no contexto do Conselho de Segurança Nacional (em inglês, National Security Council) que formulava e expunha as razões da estratégia de contenção a União Soviética (BERRYMAN, 2014; DREW, 1996).

A contenção irá se manter como um dos princípios da GE dos EUA ao longo da Guerra Fria, com modificações pontuais na intensidade e formas de ação, condicionando a atuação diplomática e militar do país. Porter (2018) chama a atenção para outros aspectos da Grande Estratégia durante a Guerra Fria, - que identifica como Primazia que demonstram a existência de um caráter político claro, a partir do qual se formulam diferentes estratégias específicas: "ser predominante militarmente; tranquilizar e conter aliado; integrar outros Estados às instituições e mercados projetados nos EUA; e inibir a propagação de armas nucleares" (PORTER, 2018: 9, tradução nossa ${ }^{11}$ ).

Retornando aos problemas da Grande Estratégia dos EUA no pós-Guerra Fria, acredita-se que o pensamento de Boyd, mais especificamente a inversão da hierarquia da realidade na sua determinação da cosmovisão e da epistemologia, bem como seu método, auxilia na compreensão da indefinição do conteúdo político e prático em GE que tem acometido a PES estadunidense desde 1991. A popularidade do Ciclo OODA nos círculos militares e estratégicos estadunidense - e enquanto método de ação humana e, no limite, do Estado -, somado a defesa boydiana da desorientação do ciclo OODA adversário pode ter tido influência na formulação e execução de uma grande estratégia indeterminada, pouco consistente e que não parece levar em conta os aspectos holísticos do Sistema Internacional.

Enquanto um conceito oriundo do nível de análise individual (a primeira imagem na visão waltziana), a generalização do Ciclo OODA para o nível estatal acarreta como ônus a supressão das mediações que envolvem os interesses políticos, o exercício da diplomacia e o uso dos recursos econômicos para garantir a sobrevivência no SI. Dessa forma, a PES, em uma tentativa de formular e fazer emergir uma grande estratégia, ficaria reduzida somente aos instrumentos militares, ou então a uma ação que permita interferir no ciclo OODA do adversário. Mesmo nas teorias realistas mais radicais, existem momentos em que os Estados devem fugir do jogo de soma-zero da política internacional. Em outras palavras, nem sempre o balanceamento - ou o conflito - é a melhor estratégia. Às vezes, a cooperação pode inclusive trazer maiores benefícios para a sobrevivência do Estado.

Historicamente, após a Segunda Guerra Mundial, os EUA possuíam um foco bastante específico de sua PES: equilibrar a balança de poder em relação ao outro polo do Sistema Internacional, a União Soviética. Sendo assim, por cerca de quatro décadas, a Grande Estratégia norte-americana tinha objetivos claros e bem trilhados. Contudo, ao longo de toda a Guerra Fria, fissuras no mundo bipolar foram abrindo brechas para ascensão de novos agentes de peso no Sistema Internacional, como a ruptura sino-soviética de 1962, a retirada da França da OTAN de 1966, a diplomacia triangular dos EUA em relação à China de 1971 e a crise

\footnotetext{
${ }^{11}$ No original:"to be militarily preponderant; to reassure and contain allies; to integrate other states into U.S.-designed institutions and markets; and to inhibit the spread of nuclear weapons".
} 
financeira de 1973-4 e a subsequente ascensão do Terceiro Mundo. O ultimato do mundo bipolar chegou com a derrocada do bloco soviético nos anos de 1989 (Queda Muro de Berlim) e de 1991 (colapso interno da URSS), fatores que levaram à multipolaridade e a uma nova guinada na Política Externa e de Segurança dos EUA. Sendo assim, diante do exposto até então, após o fim da Guerra Fria, a PES estadunidense, que antes tinha objetivos claros e bem trilhados, se reduz a instrumentos militares e táticos.

Em mundo multipolar, anárquico, desequilibrado - e por que não dizer, caótico, como definiu Visentini (2015) - o modelo metodológico e o conteúdo ontológico de Boyd parece ter se operacionalizado como diretriz da Política Externa e de Segurança dos EUA- conscientemente ou não. Afirma-se isso uma vez que as atitudes políticas e militares estadunidenses se mostraram provocadoras do caos, do pânico e do pavor $^{12}$ nas duas Guerras do Golfo (1991 e 2003) e na Invasão do Afeganistão (2001), colocando o país em um estado de guerra permanente (PECEQUILO apud JUBRAN, 2016; JOYNER, 2011; FAZAL; KREPS, 2018). Essas afirmações podem ser verificadas por meio da declaração do próprio Secretário de Defesa norteamericano Donald Rumsfeld de outubro de 2001: “a missão faz a coalizão”. A sentença de Rumsfeld caracteriza o aspecto, aparentemente, boydiano da PES dos Estados Unidos, haja vista a unilateralidade da atitude do Secretário de Defesa em relação ao processo político de alianças internacionais. Não obstante, a inversão lógica feita por Rumsfeld evidencia a prioridade da Política Externa dos Estados Unidos: o nível tático.

\section{Considerações finais}

No decorrer deste artigo, procurou-se sustentar a tese de que o pensamento de John Boyd possui potencial para investigações mais aprofundadas relacionadas à produção de teoria de RI e à Política Externa e de Segurança dos Estados Unidos. Cabe ressaltar que este trabalho se insere em um programa de pesquisa maior, e aqui que se buscou, inicialmente, apresentar e realizar um levantamento das proximidades entre a cosmovisão, a epistemologia e o método de Boyd com as ideias de Creveld, dentro da tradição idealista, e Mearsheimer, na tradição realista.

A partir do debate em torno da cosmovisão de Boyd, essencialmente distópica, traçou-se paralelos com a visão utópica de Creveld, que prevê a obsolescência do Estado enquanto ente organizado do sistema internacional. A semelhança entre ambos os autores permanece em suas conclusões preliminares a respeito do papel do Estado em um mundo utópico ou distópico. Ainda que possuam conteúdos normativos divergentes, no limite, suas cosmovisões colocam em questão os problemas advindos de um Sistema Internacional marcado pela obsolescência do Estado, e os desafios relacionados à manutenção da ordem em uma realidade assim.

No que concerne a abordagem realista de Mearsheimer, o paralelo se deu por meio das lições que Boyd retira do seu modelo de tomada de decisão racional, o Ciclo OODA, e os componentes de medo e projeção de força incluídas na perspectiva ofensiva do neorrealismo estrutural de Mearsheimer. As

\footnotetext{
${ }^{12}$ Doutrina de Choque e Pavor (ULLMAN \& WADE, 1996) - no original Shock and Awe - surgiu como legado da experiência militar estadunidense na Guerra do Golfo de 1991. Juntamente com as Operações Baseadas em Efeitos (ASH, 2001; BINGHAM, 2002), o Choque e Pavor encontra nas teses boydianas sobre o Ciclo OODA o fundamento para a aplicação do uso da força de forma precisa, localizada e almejando causar terror, através da divulgação desses efeitos e imagens.
} 
semelhanças teóricas nesse campo residem no próprio comportamento dos Estados, caracterizado como impetuoso, porquanto busquem a sobrevivência em um meio anárquico e entrópico, no qual aquele que monopolizar o processo do caos de maneira mais eficiente, tem maiores chances de sobreviver.

Tais pontos de contato demonstram a abrangência do pensamento do Boyd e acredita-se, corroboram a relevância de investigações futuras que busquem destacar semelhanças de pressupostos, conclusões preliminares e conteúdo normativo com os outros teóricos e analistas das Relações Internacionais.

No que diz respeito à Grande Estratégia dos EUA, acredita-se que, de modo preliminar, o pensamento de Boyd pode auxiliar a entender os debates realizados nos últimos anos acerca do caráter que a PES dos EUA terá. Atualmente, diversos fatos tornam prementes estudos que investiguem a formulação da Grande Estratégia estadunidense: o impacto do primeiro governo Trump e os debates em torno de uma possível reeleição; a manutenção dos EUA em diversos conflitos iniciados no início deste século; a intensificação dos debates em torno de um retorno a um isolacionismo americano (LIND, WOHLFORTH, 2019); intensificação das disputas de poder com a China, entre outros.

Por fim, cumpre esclarecer que a possível influência de John Boyd na PES estadunidense é certamente um aspecto que se gostaria de ver refutado pela realidade, uma vez que parece ter conduzido a liderança estadunidense no mundo a um momento particularmente sensível. Contudo, desde logo, cabe ressalvar que seria inadequado atribuir primordialmente a sua, eventual, influência os descaminhos da PES e da doutrina nos EUA.

\section{REFERÊNCIAS}

ASH, Eric. A Seleção de Alvos com o Intuito de Provocar o Terror: o moral da história. Air\&Space Power Journal em Português, Maxwell AFB, $2^{\circ}$ Trimestre 2001. Disponível em: http://www.au.af.mil/au/afri/aspj/apjinternational/apj-p/2001/2tri01/ash.htm. Acesso em: 14 fev. 2019.

BINGHAM, Price T. Transformar a Guerra com Operações Combinadas Baseadas nos Efeitos. Air\&Space Power Journal em Português, Maxwell AFB, $3^{\circ}$ Trimestre 2002. Disponível em: http://www.au.af.mil/au/afri/aspj/apjinternational/apjp/2002/3tri02/bingham.htm. Acesso em: 14 fev. 2019.

BERRYMAN, Craig. The Search for a Cold War Grand Strategy: NSC 68 \& 162. 2013. 94 f. Monografia (Especialização) - School of Advanced Military Studies, United States Army Command And General Staff College, Fort Leavenworth, 2014. Disponível em: <https://apps.dtic.mil/dtic/tr/fulltext/u2/a612719.pdf>. Acessoem: 12 set. 2019.

BOYD, John Richard. Destruction and Creation. [S.l.], 3 Sept. 1976. Disponível em:http://goalsys.com/books/documents/DESTRUCTION_AND_CREATION.pdf. Acesso em:14 fev. 2019.

BOYD, John Richard. Essence on Winning and Losing. [S.1], 2012. Versão apresentada emJan. 1996. Disponível em:http://fasttransients.files.wordpress.com/2010/03/essence_of_winning_losing.pdf Acesso em:14 fev. 2019. 
BOYD, John Richard. Organic Design for Command and Control. [S.l], Feb. 2005. Versãoapresentada em May 1987. Disponível emhttps://www.ausairpower.net/JRB/organic_design.pdf. Acesso em: 14 fev. 2019.

BOYD, John Richard. Patterns of Conflict. [S.1], Dec. 1986. Disponível em:http://www.ausairpower.net/JRB/poc.pdf. Acesso em 14 fev. 2019.

CORAM, Robert. Boyd: The Fighter Pilot Who Changed the Art of War. Nova York: Little, Brown \& Company, 2002.

CREVELD, Martin van. Ascensão e Declínio do Estado. São Paulo: Martins Fontes, 2004.

CREVELD, Martin van. Command in War. Cambridge: Harvard University Press, 1987.

CREVELD, Martin van. More on War. New York: Oxford University Press, 2017.

CREVELD, Martin van.The Transformation of War. New York: The Free Press, 1991.

DREW, Nelson (Ed.). NSC 68: Forging the Strategy of Containment. 2. ed. Washington D.c: National Defende University, 1996. Disponível em: <https://www.files.ethz.ch/isn/139678/199409_NSC68_Forging_Strategy.pdf $>$. Acesso em: 12 set. 2019.

FAZAL, Tanisha M.; KREPS, Sarah. The United States' Perpetual War in Afghanistan. Foreign Affairs. Washington D.C., 20 ago. 2018. Disponível em: <https://www.foreignaffairs.com/articles/northamerica/2018-08-20/united-states-perpetual-war-afghanistan>. Acesso em: 12 set. 2019.

FRIEDMAN, Benjamin H.; LOGAN, Justin. Why Washington Doesn't Debate Grand Strategy. Strategic Studies Quarterly, Washington D.C., v. 10, n. 4, p.14-45, dez. 2016. Disponível em: <https://www.cato.org/sites/cato.org/files/articles/ssq_1216_friedman.pdf>. Acesso em: 12 set. 2019.

HAMMOND, Grant T. The Mind of War: John Boyd and American Security. Washington D.C.: Smithsonian Books, 2001.

HOOKER JUNIOR, R.D. The Grand Strategy of the United States. Washington D.C: National Defence University Press, 2014. (INSS StrategicMonograph). Disponível em: <https://inss.ndu.edu/Portals/68/Documents/Books/grand-strategy-us.pdf >. Acesso em: 12 set. 2019.

JAPIASSÚ, Hilton; MARCONDES, Danilo. Dicionário Básico de Filosofia. 5aed. Rio de Janeiro: Zahar, 2008.

JAROSZEWSKI, Rodrigo. O Ciclo OODA. Metódico, [S.l.], 6 mar. 2017.Disponível em: https://rodrigolj.wordpress.com/2017/03/06/o-ciclo-ooda/. Acesso em: 01 abr.2018.

JOYNER, James. How Perpetual War Became U.S. Ideology. The Atlantic. [S.l]. 11 maio 2011. Disponível em: <https://www.theatlantic.com/international/archive/2011/05/how-perpetual-war-became-usideology/238600/>. Acesso em: 12 set. 2019.

JUBRAN, Bruno Mariotto. Estados Unidos: “em guerra permanente”. Panorama Internacional FEE, Porto Alegre, v.2,n.2, 2016. Disponível em:<http://panoramainternacional.fee.tche.br/article/estadosunidos-em-guerra-permanente/>. Acesso em: 12 set. 2019.

LAKATOS, Imre. Falsification and the Methodology of Scientific Research Programmes. In: LAKATOS, Imre; MUSGRAVE, Alan. Criticism and the Growth of Knowledge. New York: Cambridge University Press, 1970. [pp. 91-196.] 
LEAVY, Patricia. Introduction. In: LEAVY, Patricia (ed.). The Oxford Handbook of Qualitative Reasearch. Nova York: Oxford University Press, 2014.[pp. 1-13].

LIND, Jennifer; WOHLFORTH, William C. The Future of the Liberal Order Is Conservative: A Strategy to Save the System. Foreign Affairs, [s.l], v. 98, n. 2, p.70-81, mar. 2019. Disponível em: $<$ https://www.foreignaffairs.com/articles/2019-02-12/future-liberal-order-conservative>. Acesso em: 16 ago. 2019.

LIND, Willian S. et al. The Changing Face of War: into the fourth generation. Military Review, Forth Leavenworth, v. 69, n. 10, p.2-11, 1989.

MARSH, David; FURLONG, Paul. A Skin not a Sweater: Ontology and Epistemology in Political Science. In. MARSH, David; STOKER, G. (eds). Theory and Methods in Political Science. Hampshire: Palgrave Macmillan, 2002. [pp. 17-41].

MARTEL, William C. Grand Strategy in Theory and Practice: the need for an effective American Foreign Policy. New York: Cambridge University Press, 2015.

MARTINS, José Miguel; CEPIK, Marco. A. Defesa Nacional Antimíssil dos EUA: A lógica da Preempção e Suas Implicações Internacionais. In: ARTURI, C. Políticas de Defesa, Inteligência e Segurança. Porto Alegre: UFRGS/CEGOV, 2014. p. 14-47.

MEARSHEIMER, John J.A Tragédia da Política das Grandes Potências. Lisboa: Gradiva, 2007.

MEARSHEIMER, John J. Maneuver, Mobile Defense and the NATO Central Front. International Security, Vol. 6, $\mathrm{N}^{\circ}$. 3. Inverno de 1982. pp.: 104 - 122. Disponível em: <http://mearsheimer.uchicago.edu/pdfs/A0005.pdf >. Acesso em: 10/12/2013.

MEARSHEIMER, John J.The Military Reform Movement: A Critical Assessment. ORBIS, [S.l], v. 27, n. 2.p. 285-300, 1983.Disponívelem:http://mearsheimer.uchicago.edu/pdfs/A0007.pdf. Acesso em: 10 fev. 2017.

MEARSHEIMER, John J. War with Iraq Is Not in America's National Interest. New York Times. 26 de Setembro de 2002.

MONTGOMERY, Evan Braden. Contested Primacy in the western Pacific: China's Rise and the Future of U.S. Power Projection. International Security, v. 38, n. 4 p.115-149, Spring 2014.

OSINGA, Frans. Science, strategy and war: The strategic theory of John Boyd. Delft: Eburon Academic Publishers, 2005. Disponível em: <http://chicagoboyz.net/blogfiles/OsingaBoydThesis.pdf>.

PASHAKHANLOU,ArashHeydarian. Realism and Fear in International Relations: Morgenthau, Waltz and Mearsheimer Reconsidered. Suíça: Palgrave Macmillan, 2017.

PORTER, Patrick. Sharing Power? Prospect for a U.S. Concert-Balance Strategy. Carlisle: U.S. War College Press, 2013.

PORTER, Patrick. Why America's Grand Strategy Has Not Changed: Power, Habit, and the U.S. Foreign Policy Establishment. International Security, [s.1.], v. 42, n. 04, p.9-46, maio 2018. MIT Press Journals. Disponível em: <https://www.mitpressjournals.org/doi/pdf/10.1162/isec_a_00311>. Acessoem: 12 set. 2019.

RICHARDS, Chet. Certain to Win: The Strategy of John Boyd, Applied to Business. [S.1]: Xlibris, Corp., 2014. 
RONIS, Sheila (Ed.). Forging an American Grand Strategy: Securing a Path Through a Complex Future. Carlisle Barracks: Strategic Studies Institute; U.s. Army War College Press, National Defense University, 2013.

RUSSET, Bruce. Grasping the Democratic Peace: Principles for a Post-Cold War World. Princeton: Princeton University Press, 1993.

SCHECHTMAN, Gregory M. Manipulating the Ooda Loop: the Overlooked Role Of Information Resource Management in Information Warfare. Dissertação (Mestrado em Gestão de Recursos de Informação) - Air University, Maxwell. 1996.

SIMIONATO, Guilherme; MACHADO, Luis Rodrigo. Da Importância de uma Grande Estratégia: O Caso Estadunidense e a Ascensão Chinesa. $1^{\circ}$ Seminário Internacional de Ciência Política. Porto Alegre: UFRGS, 2015.

ULLMAN, Harlan K.; WADE, James P. ShockandAwe: AchievingRapidDominance. Washington D.C.: National Defense University, 1996.

VISENTINI, Paulo Fagundes. O Caótico Século XXI. Rio de Janeiro, Alta Books, 2015.

WALT, Stephen M. US grand strategy after the Cold War: Can realism explain it? Should realism guide it?.International Relations, [s.l.], v. 32, n. 1, p.3-22, 23 jan. 2018. SAGE Publications.

WALTZ, Kenneth. Theory of International Politics. Long Grove: Waveland Press, 1979.

YETIV, Steve A. The Absence of Grand Strategy: the United States in the Persian Gulf, 1972-2005. Baltimore: John Hopkins University Press, 2008. 


\section{RESUMO}

O trabalho objetiva discutir possíveis influências do pensamento de John Boyd na Política Externa e de Segurança (PES) dos Estados Unidos (EUA). O problema de pesquisa é investigar a relação da cosmovisão de Boyd com aspectos presentes na PES dos EUA pós-1991. Analisa-se brevemente a cosmovisão, a epistemologia e o método no pensamento de Boyd. Em seguida, buscam-se os pontos de contato com as tradições idealistas e realistas de Relações Internacionais, especificamente com as obras de Martin van Creveld e John Mearsheimer. Por fim, discute-se o possível impacto da epistemologia boydiana e do Ciclo OODA na ausência de uma grande estratégia dos EUA no pós-Guerra Fria. Defende-se que o pensamento de Boyd dialoga com o idealismo por meio de um mundo onde predomina o caos, no caso de Boyd, e sem o Estado-nação, como propõe Creveld. Quanto aos realistas, o paralelo reside no papel da projeção de força e do medo como elemento da PES. Por fim, quanto à grande estratégia, a inversão da hierarquia da realidade (da tática para a estratégia, do combate para a política) realizada por Boyd, além de sua cosmovisão e epistemologia, teria contribuído para o predomínio de soluções simplificadoras na PES dos EUA.

Palavras-chave:John Boyd; Política Externa e de Segurança dos EUA; Grande Estratégia.

\section{ABSTRACT}

The paper aims to discuss possible influences of John Boyd's thinking on the United States Foreign and Security Policy (FSP). The research problem is to investigate the relationship of Boyd's cosmovision - the promotion of chaos and the increase of entropy - with aspects of American FSP post-1991. The cosmovision, epistemology and method in Boyd's thinking are briefly analyzed. Then the points of contact with the Idealism and Realism theories are sought, and finally discussed the reasons for the absence of a American grand strategy. The main argument is that the thought of Boyd allows us to draw several relations with theorists who influenced the US Foreign and Security Policy. As for idealistic tradition, this occurs through a world dominated by chaos, in Boyd's case, and without the nation-state, as Creveld proposes. With neorealists, the parallel is between the role of power projection and fear as an element of US foreign policy. Finally, with regards to US grand strategy, Boyd's influence may lie in the inversion of the hierarchy of reality (from tactics to strategy, from combat to politics), in addition to his cosmovision and epistemology, that would have contributed to the predominance of simplifying solutions in the US FSP.

Key-words: John Boyd, US Foreign and Security Policy, Grand Strategy.

\section{COPYRIGHT:}

Este é um artigo publicado em acesso aberto e distribuído sob os termos da Licença de Atribuição Creative Commons, que permite uso irrestrito, distribuição e reprodução em qualquer meio, desde que o autor e a fonte originais sejam creditados.

This is an open-access article distributed under the terms of a Creative Commons Attribution License, which permits unrestricted use, distribution, and reproduction in any medium, provided that the original author and source are credited.

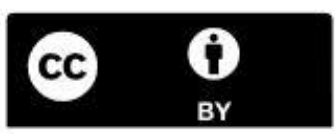

